\title{
New Nibbles A Guide to Feeding Infants
}

LUCIA KAISER, UCCE Nutrition Specialist,

Department of Nutrition, UC Davis

The New Nibbles card set provides a hands-on, educational activity to train nutrition and health educators about developmentally appropriate infantfeeding practices. Before the workshop, print and separate the cards onto individual sheets of paper (preferably card stock). Make enough copies so that a set is available for each pair of participants. During the workshop, ask participants to get into pairs and match the cards by age (black letters), developmental stage (pink letters), and appropriate infant-feeding advice (green letters). The three cards can then be clipped together, with the age card on the top. Discuss with the participants the connections between developmental readiness, nutrition needs, and appropriate infant-feeding advice.

Recommendations related to infant feeding differ across countries (Grimshaw et al. 2009). In this activity, primarily designed for U.S. populations, the American Academy of Pediatrics (AAP) has been the source for appropriate infant-feeding practices (Kleinman 2009). The focus of this information is on the introduction of solids into the diet of normal, healthy infants, and it does not cover specific recommendations for vitamin or mineral supplements. That information can be located elsewhere (Baker et al. 2010; Wagner et al. 2008).

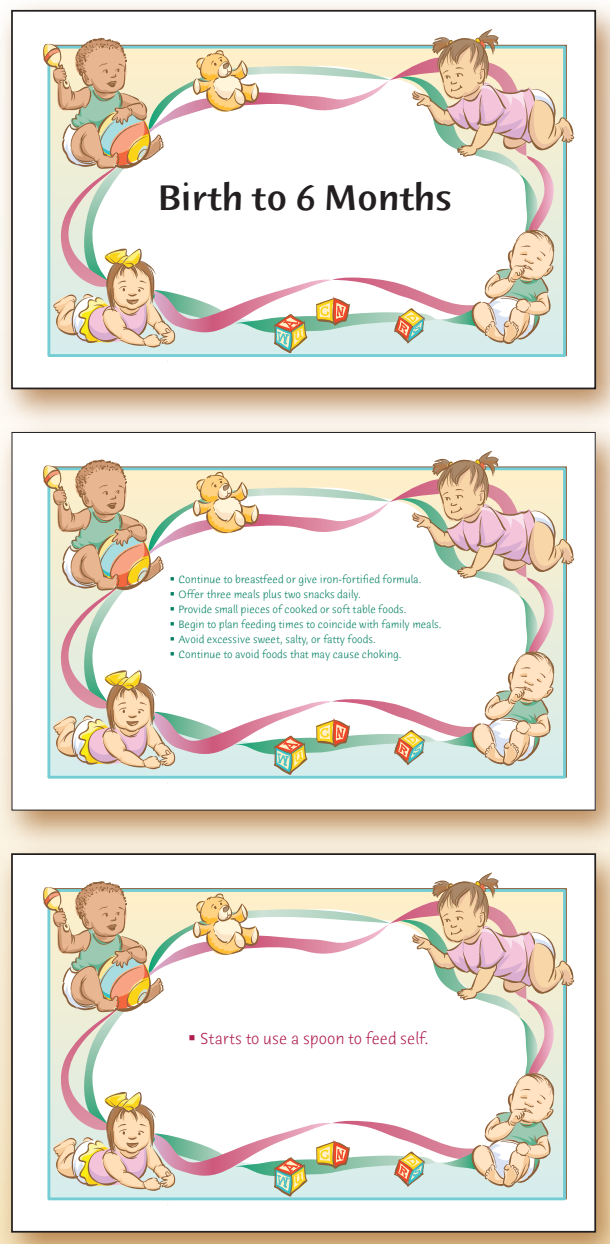




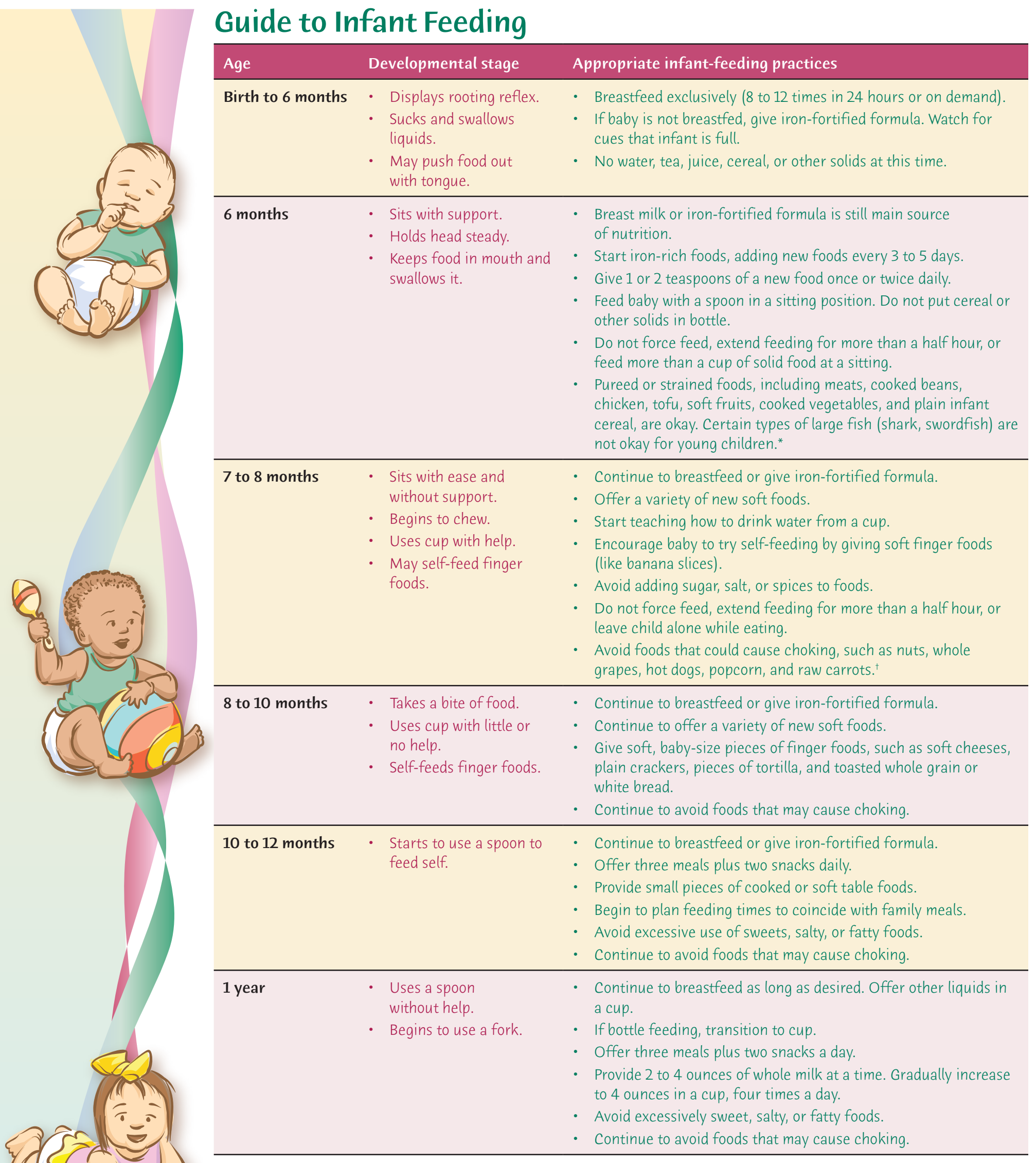

Notes: * Certain large fish are to be avoided in the diet of all young children due to the high mercury content. Other seafood, like canned salmon, pollock, or shrimp, contains less mercury and may be consumed.

† The American Academy of Pediatrics recommends avoiding foods that may cause choking in children under 4 years of age. In toddlers, some of these foods (like grapes) may be safe when cut into very small pieces. 


\section{References \\ Baker, R. D., Greer, F. R., and the Committee on Nutrition. 2010. Diagnosis and prevention of iron deficiency and iron-deficiency anemia in infants and young children (0-3 years of age). Pediatrics 126(5): 1040-1050. \\ Gartner, L. M., Morton, J., Lawrence, R. A., Naylor, A. J., O’Hare, D., Schanler, R. J., Eidelman, A. I., and the American Academy of Pediatrics Section on Breastfeeding. 2005. Breastfeeding and the use of human milk. Pediatrics 115(2): 496-506. \\ Greer, F. R., Sicherer, S. H., Burks, A. W., and the Committee on Nutrition and Section on Allergy and Immunology. 2008. Effects of early nutritional interventions on the development of atopic disease in infants and children: The role of maternal dietary restriction, breastfeeding, timing of introduction of complementary foods and hydrolyzed formulas. Pediatrics 121(1): 183-191. \\ Grimshaw, K. E. C., Allen, K., Edwards, C. A., Beyer, K., Boulay, A., Van Der Aa, L. B., Sprikkelman, A., Belohlavkova, S., Clausen, M., Dubakiene, R., Duggan E., Reche, M., Marino, L. V., Nørhede, P., Ogorodova, L., Schoemaker, A., Stanczyk-Przyluska, A., Szepfalusi, Z., Vassilopoulou, E., Veehof, S. H. E., Vlieg-Boerstra, B. J., Wjst, M., and A. E. J. Dubois. 2009. Infant feeding and allergy prevention: A review of current knowledge and recommendations. A EuroPrevall state of the art paper. Allergy 64(10): 1407-1416.}

Kleinman, R. E., ed. 2009. The pediatric nutrition handbook. 6th ed. Elk Grove Village, IL: American Academy of Pediatrics.

Wagner, C. L., Greer, F. R., the American Academy of Pediatrics Section on Breastfeeding, and the American Academy of Pediatrics Committee on Nutrition. 2008. Prevention of rickets and vitamin D deficiency in infants, children, and adolescents. Pediatrics 122(5): 1142-1152.

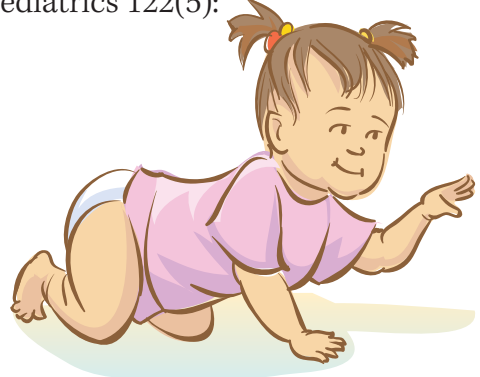

\section{For More Information}

To order or obtain ANR publications and other products, visit the ANR Communication Services online catalog at http://anrcatalog. ucanr.edu or phone 1-800-994-8849. You can also place orders by mail or FAX, or request a printed catalog of our products from

\author{
University of California \\ Agriculture and Natural Resources \\ Communication Services \\ 1301 S. 46th Street \\ Building 478 - MC 3580 \\ Richmond, CA 94804-4600 \\ Telephone 1-800-994-8849 \\ 510-665-2195 \\ FAX 510-665-3427 \\ E-mail: anrcatalog@ucanr.edu
}

()ㅣㄹ The Regents of the University of California Agriculture and Natural Resources

All rights reserved.

\section{Publication 8487}

ISBN-13: 978-1-60107-824-7

The University of California Division of Agriculture \& Natural Resources (ANR) prohibits discrimination against or harassment of any person participating in any of ANR's programs or activities on the basis of race, color, national origin, religion, sex, gender identity, pregnancy (which includes pregnancy, childbirth, and medical conditions related to pregnancy or childbirth), physical or mental disability, medical condition (cancer-related or genetic characteristics), genetic information (including family medical history), ancestry, marital status, age, sexual orientation, citizenship, or service in the uniformed services (as defined by the Uniformed Services Employment and Reemployment Rights Act of 1994: service in the uniformed services includes membership, application for membership, performance of service, application for service, or obligation for service in the uniformed services) or any person in any of its programs or activities.

University policy also prohibits retaliation against any employee or person participating in any of ANR's programs or activities for bringing a complaint of discrimination or harassment pursuant to this policy. This policy is intended to be consistent with the provisions of applicable State and Federal laws.

Inquiries regarding the University's equal employment opportunity policies may be directed to Linda Marie Manton, Affirmative Action Contact, University of California, Davis, Agriculture and Natural Resources, One Shields Avenue, Davis, CA 95616, 530-752-0495. For information about ordering this publication, telephone 1-800-994-8849.

An electronic copy of this publication can be found at the ANR Communication Services catalog website, http://anrcatalog.ucanr. edu.

UC This publication has been anonymously peer PEER reviewed for technical accuracy by University of REVIEWED California scientists and other qualified professionals. This review process was managed by the ANR Associate Editor for Food and Nutrition, Cathi Lamp. 

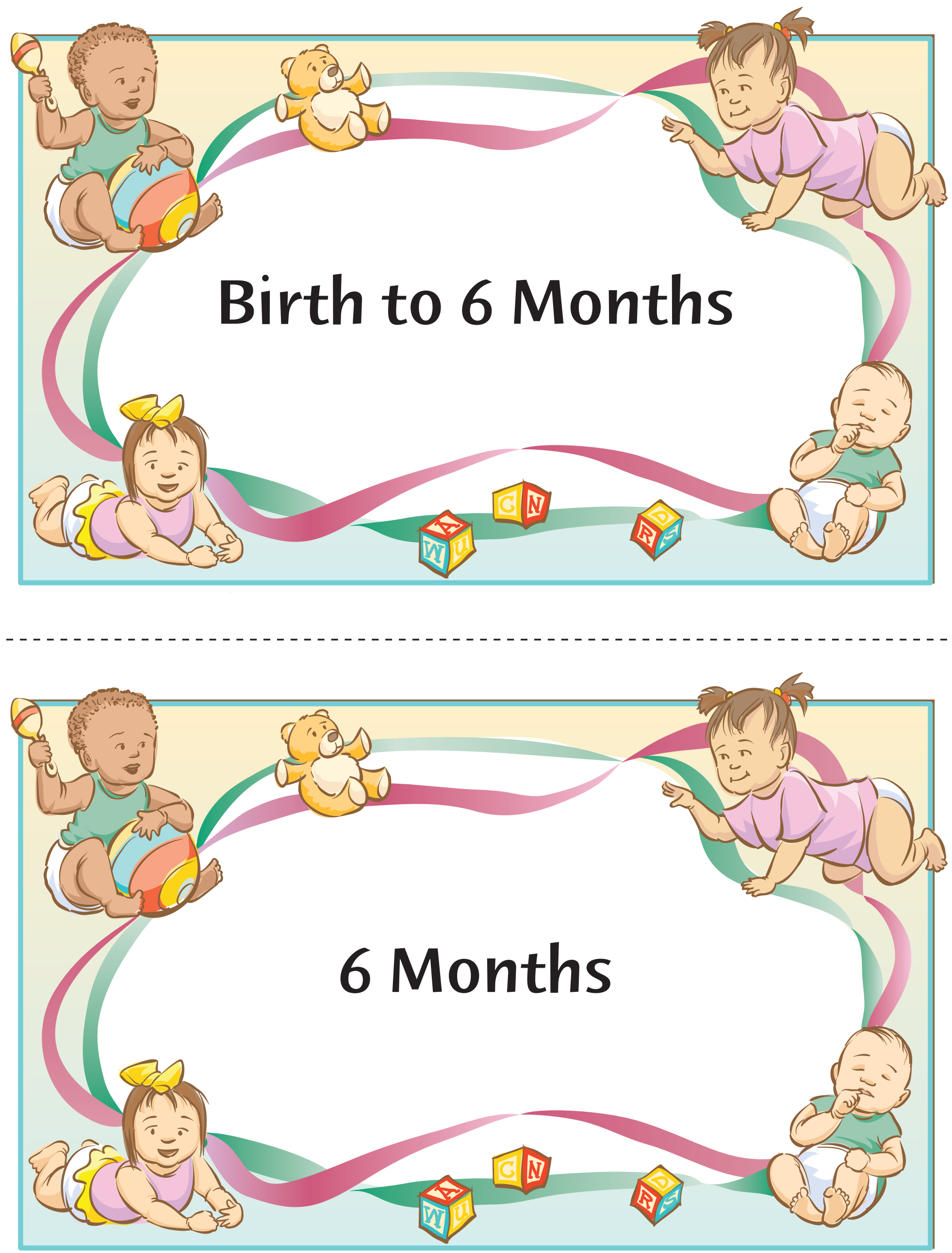

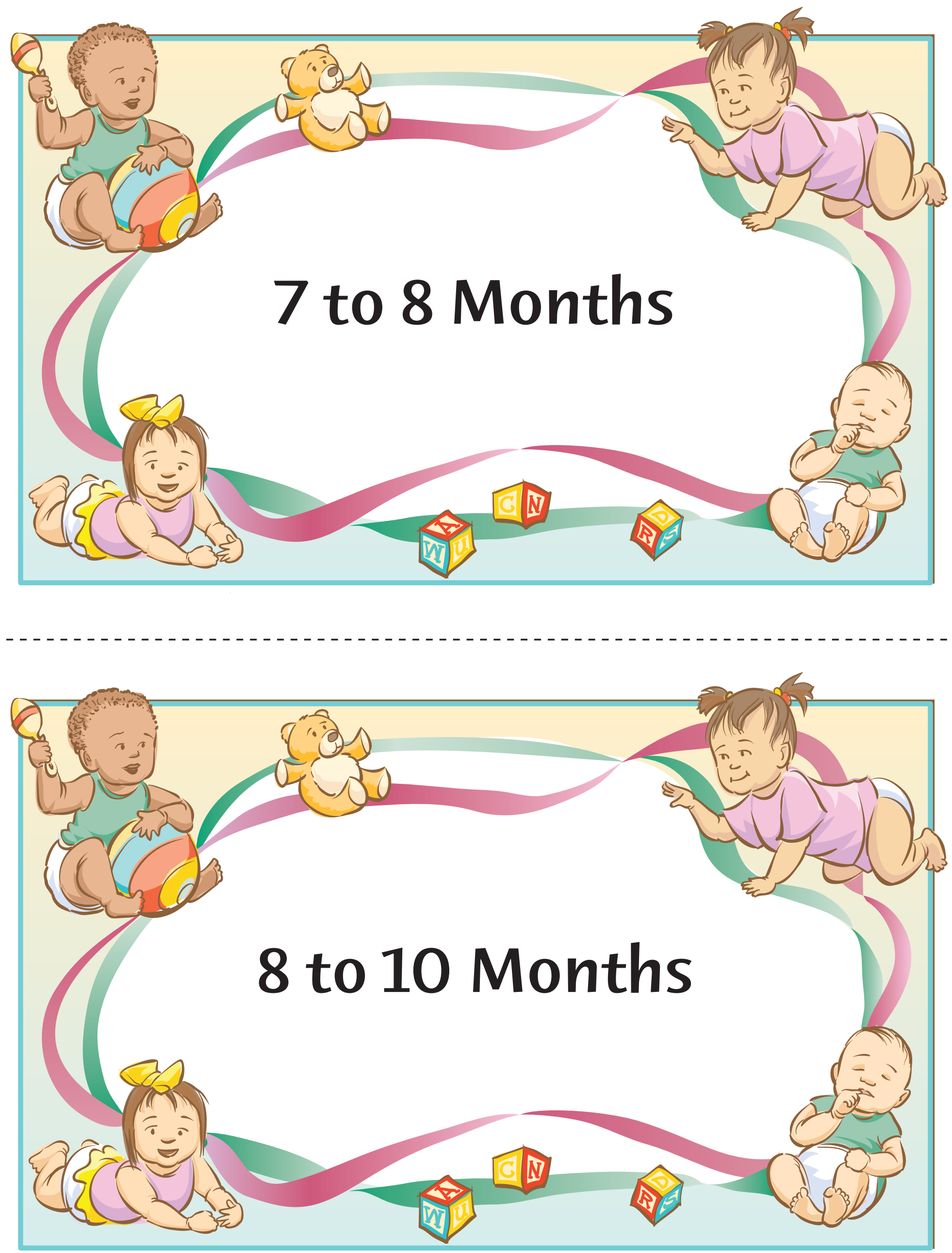

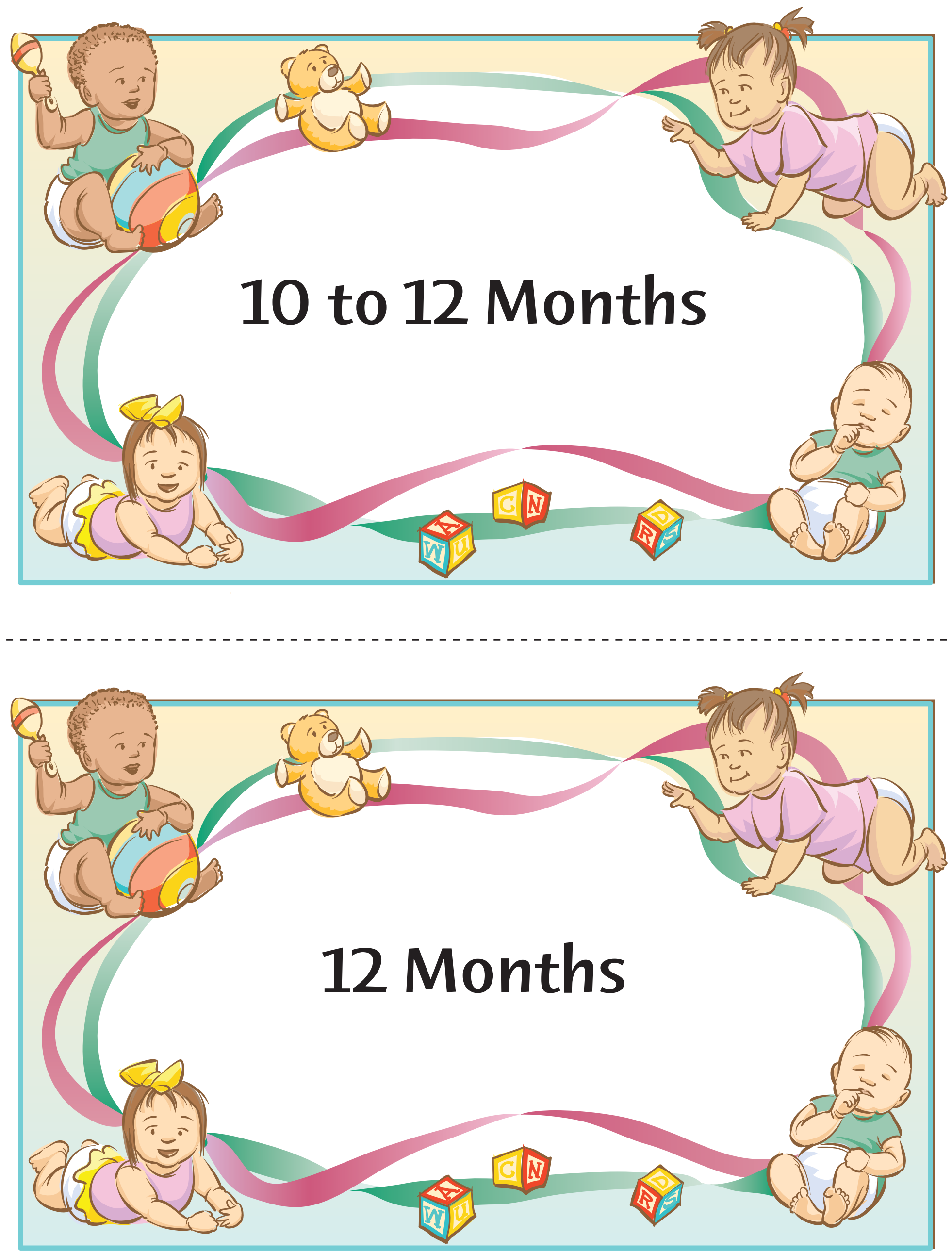

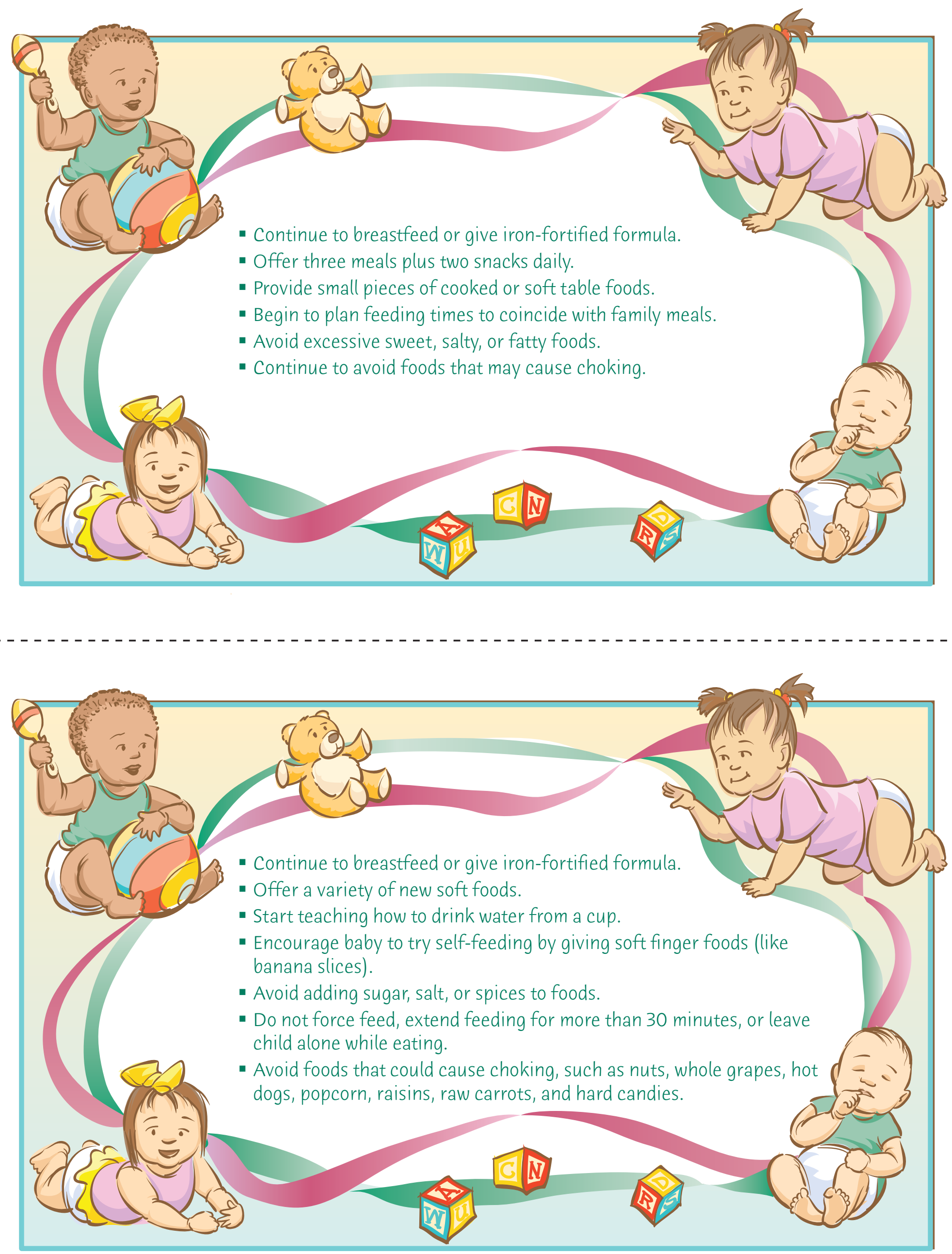

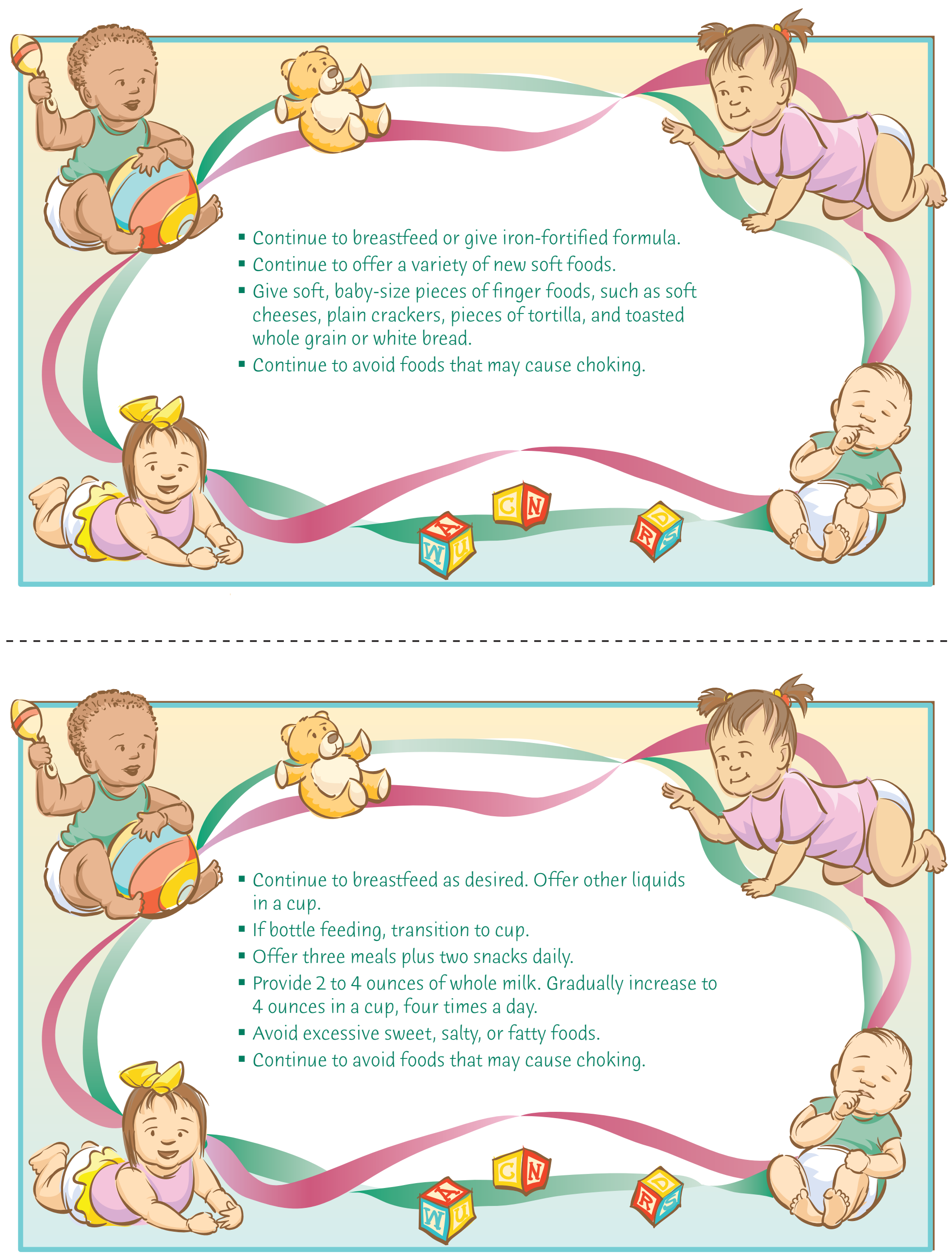

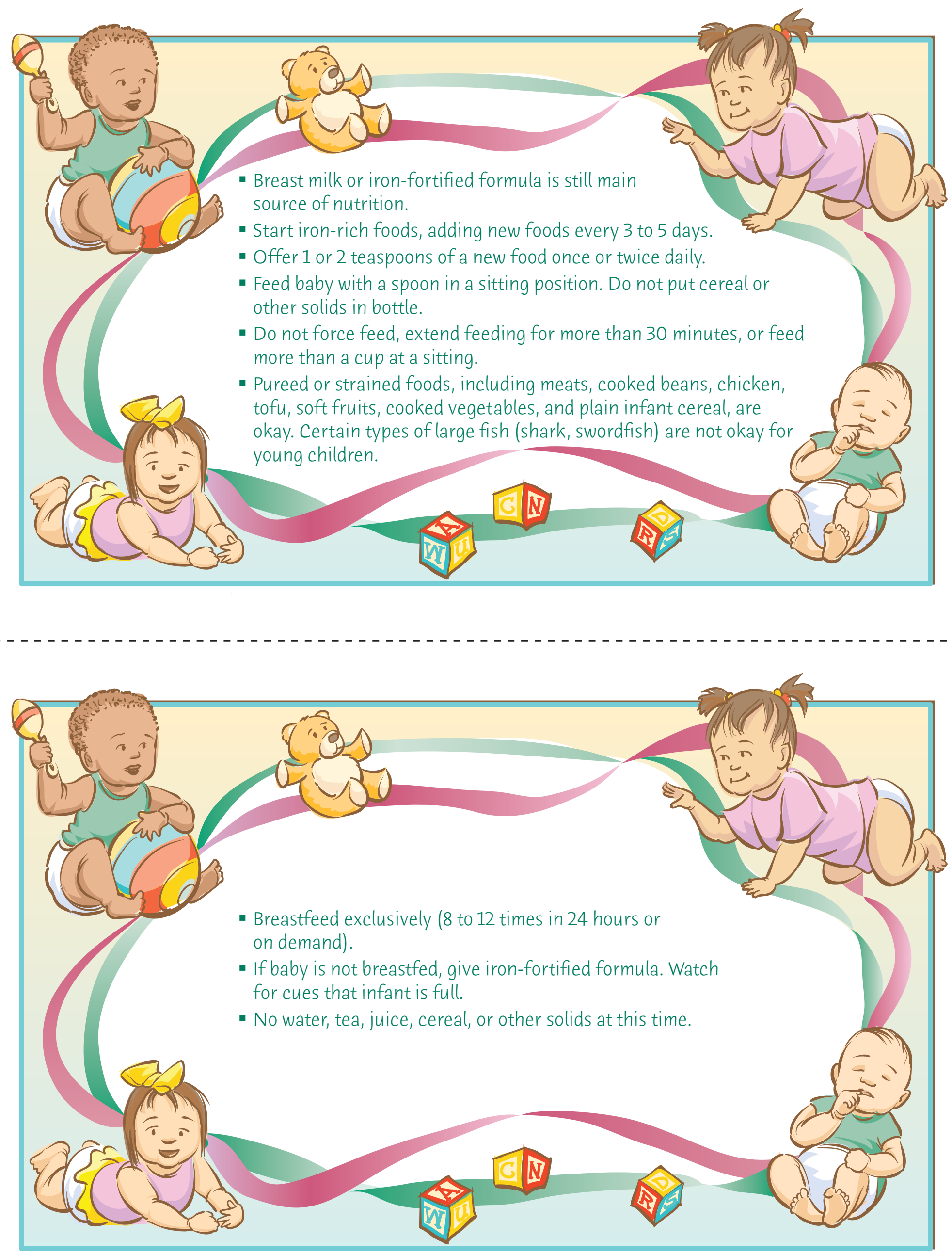

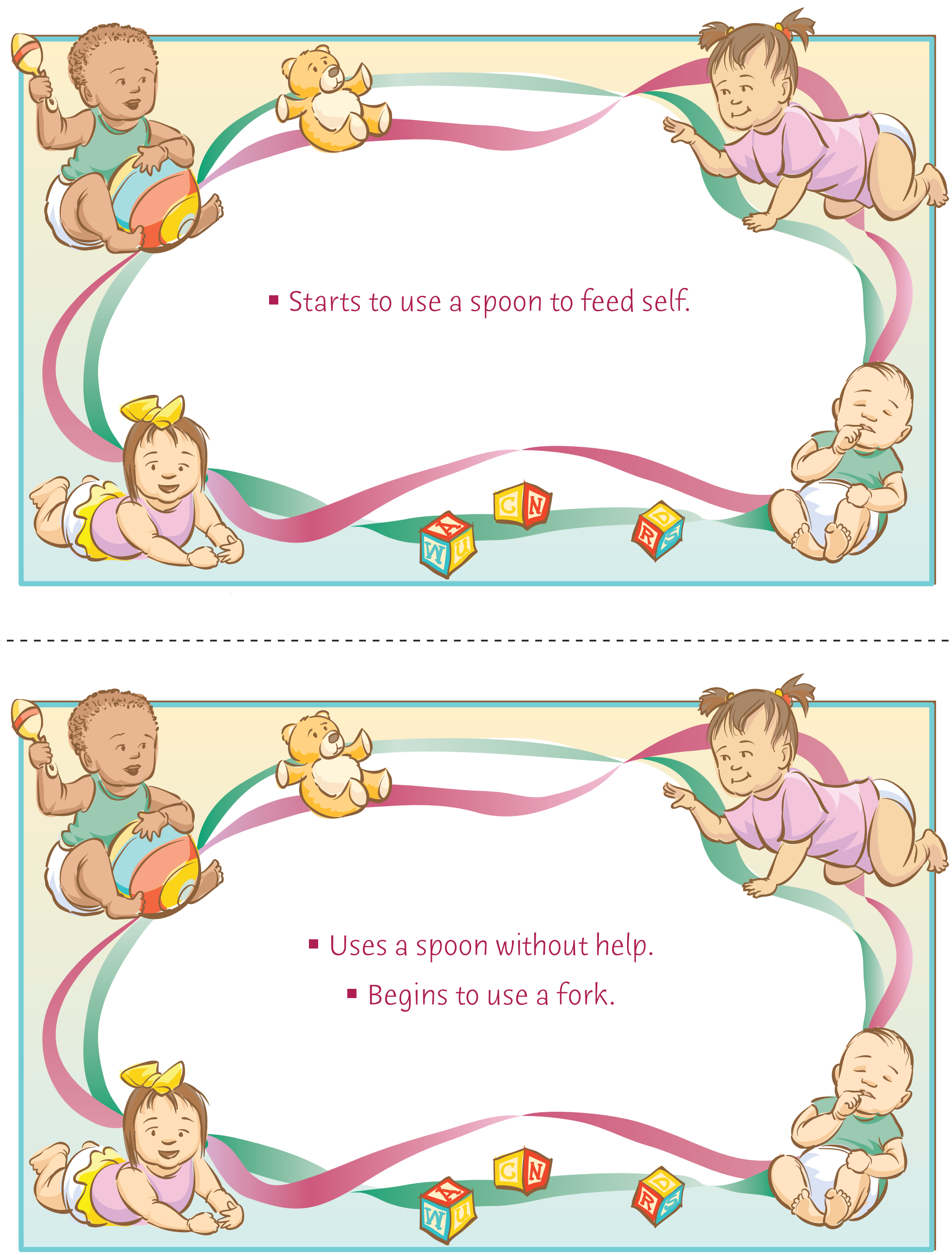

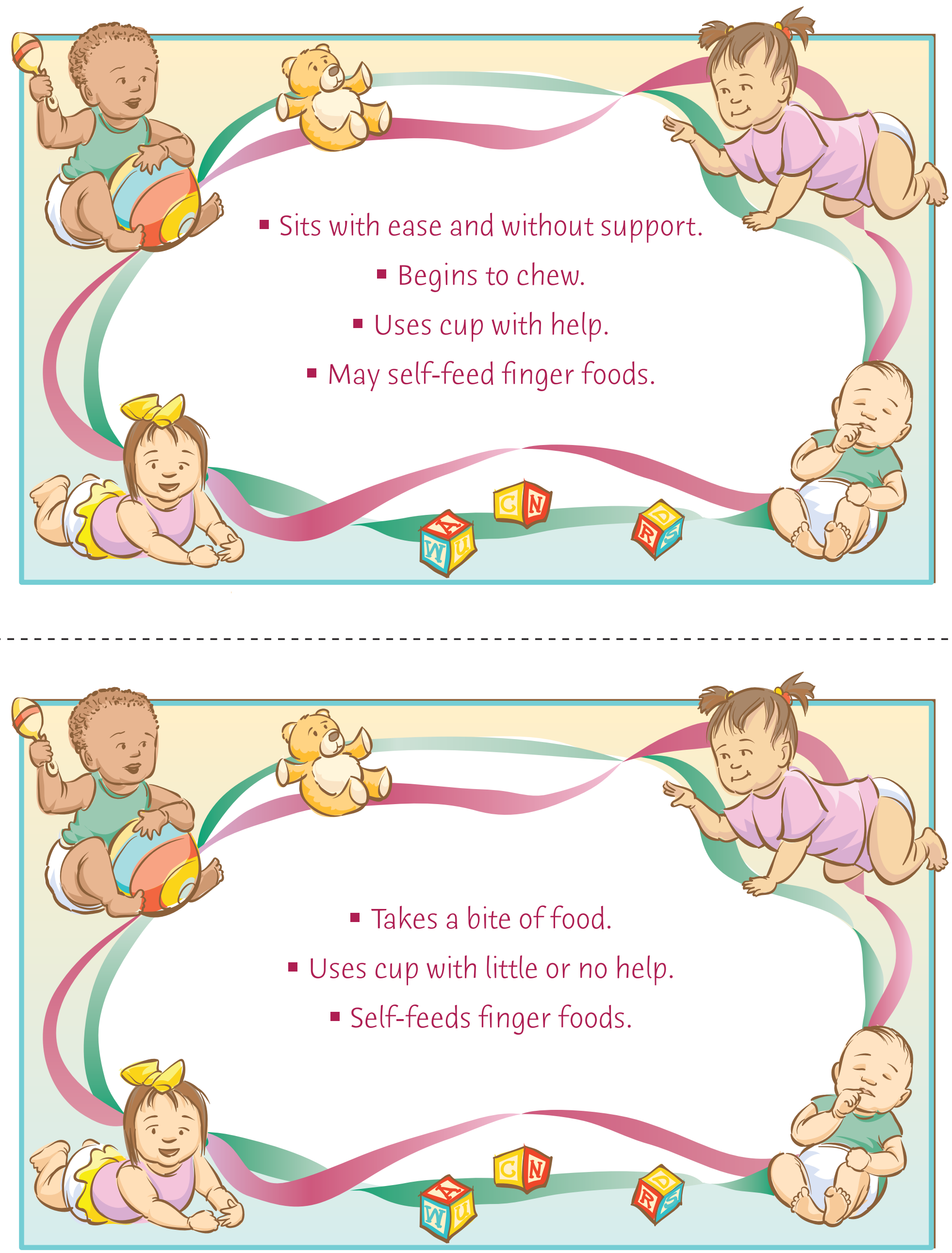

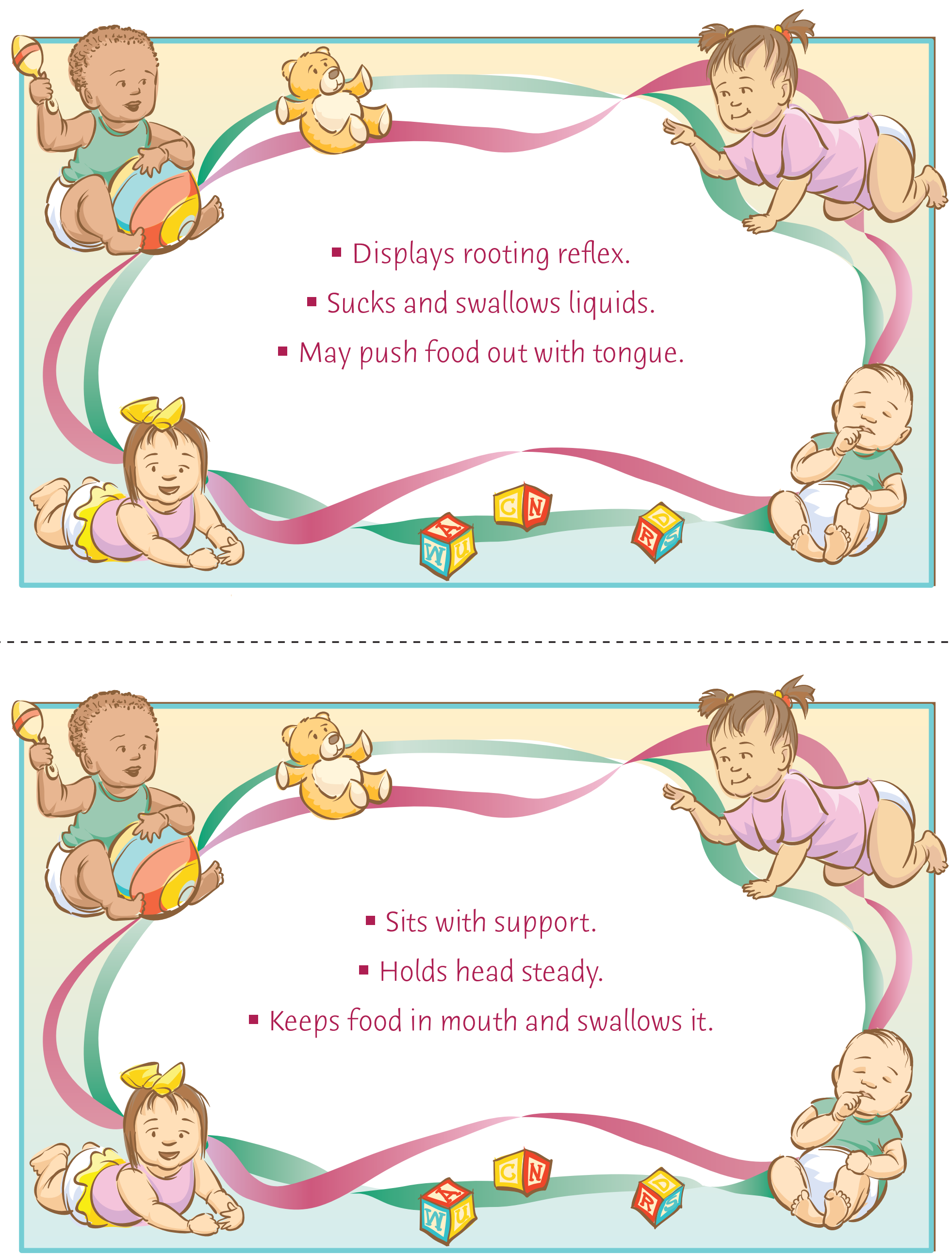